\title{
Preface to the Special Issue of Geochemistry International no. 13.
}

DOI: $10.1134 / \mathrm{S} 0016702916130048$

The papers included in this special issue of the journal focus primarily on the methodology of the analysis of natural samples.

Because the authors of the papers presented here are mostly from the Vernadsky Institute of Geochemistry and Analytical Chemistry, Russian Academy of Sciences (GEOKhI), this issue begins with a review paper on the main scientific results of the institute in the period 2011-2015, which was reported at the meeting of the GEOKhI's Academic Council on November 30, 2015. It provides a detailed overview of methodological issues, which constitute an important part of research conducted at the Institute.

The Institute conducts research within two scientific disciplines: geochemistry and analytical chemistry-each one is fairly independent, has distinctly different goals and solves different problems. The multi-year collaborative efforts of different research groups gave way to a unique school of thought, which allowed the Institute to develop expertise on a broad range of problems, from topics related to space exploration, planetology, and meteoritics to studies of ocean and water resources and the problems of Earth's core and mantle, radioactive waste disposal, radiochemical technologies, biogeochemistry, origin of life, petroleum geology and organic geochemistry, etc.

With such a diverse and rich research platform, the Institute primarily relies on the high level of experimental and methodological work, which constitutes the main focus of this special issue.

Academician E.M. Galimov 